Int. J. Dev. Biol. 61: 121-126 (2017)

doi: $10.1387 / \mathrm{ijdb} .160179 \mathrm{ok}$

\title{
Hefzibah Eyal-Giladi (1925-2017): over fifty years of embryological research in Israel
}

\author{
ODED KHANER* \\ Department of Health and Life Sciences, Hadassah Academic College, Jerusalem, Israel
}

\begin{abstract}
Hefzibah Eyal-Giladi was a creative and innovative pioneering scientist in the creation of the field of early chick embryo development. She had a sharp thinking and enthusiastic attitude, which enabled her to make a deep impression that was highly valued by the general scientific community. Notably, she was a highly successful female researcher in an era which was dominated by male scientists. Her unique personality and keen intellect enabled her to break these borders in a most successful manner. The experiments conducted by her personally, her students and her collaborators served to provide the basic knowledge and paradigms for future scientists in the field, also paving the way for discoveries in other vertebrate model systems. The experimental embryology assays she performed were "old school", examining embryos and explants at a precise morphological level of tissue interactions. In recent years, most of the experimentation in embryology has shifted to molecular and genetic levels. However, the results obtained with these technologically advanced research tools still re-confirm the fundamental findings obtained by Eyal-Giladi using "classic" experimental embryology techniques. Finally, Hefzibah Eyal-Giladi was an outstanding teacher and lecturer. For five decades, she trained and taught generations of undergraduate and graduate students in Israel, exposing them to the field of embryology and developmental biology in the most exciting and enthusiastic way.
\end{abstract}

KEY WORDS: chick embryology, bilateral symmetry, axis initiation, mesoderm induction, chordate body axis

Dedicated to the memory of Hefzibah Eyal-Giladi, a beloved teacher and colleague, and a great scientist.

\section{Introduction}

Hefzibah Eyal-Giladi was an internationally esteemed pioneer researcher and founder leader in the fields of embryology and developmental biology in Israel and all over the world (Fig. 1). She was born in pre-state Israel in 1925, and in the 1940's she performed her undergraduate studies in biology at the Hebrew University of Jerusalem. She finished her undergraduate studies after the Israel War of Independence in 1948. She then moved to the Netherlands and performed her graduate studies in the laboratory of Professor Pieter Nieuwkoop (Hubrecht laboratory at Utrecht University), one of the most renowned embryologists of the $20^{\text {th }}$ century (Fig. 2). Her Ph.D. thesis topic was, "Dynamic Aspects of Neural Induction in Amphibia" (Eyal-Giladi H., 1954). Her thesis was groundbreaking research, examining the earliest aspects of neural patterning in a vertebrate system. Her model of early neural patterning published in 1954 is still a paradigm in the field over sixty years later.

Eyal-Giladi returned to Israel in 1955, receiving an academic appointment in the Department of Zoology, The Hebrew University of Jerusalem. In the next few years, she continued her studies in amphibian development, concentrating mainly on the development of the muscular and nervous systems (Eyal-Giladi et al., 1964). In the early 1960's, her sabbatical research took her to the USA, where at the University of Minnesota she worked with Nelson Spratt, one of the pioneering scientists in the field of chick development. They explored the potential of investigating early chick development as a model vertebrate system (Eyal-Giladi and Spratt, 1965).

After her sabbatical and subsequent return to Israel, Eyal-Giladi continued her studies on the early stages of chick development (Eyal-Giladi, 1969; Eyal-Giladi, 1970; Eyal-Giladi, 1970). Her research for the next forty years concentrated mainly on differ-

Abbreviations used in this paper: $\mathrm{PGC}$, primordial germ cell; PMZ, posterior marginal zone.

\footnotetext{
*Address correspondence to: Oded Khaner. Department of Health and Life Sciences, Hadassah Academic College, Jerusalem 919100, Israel.

E-mail: odedk@hadassah.ac.il - iD http://orcid.org/0000-0003-1637-3496
}

Accepted: 1 June 2016.

ISSN: Online 1696-3547, Print 0214-6282

(C) 2017 UPV/EHU Press

Printed in Spain 

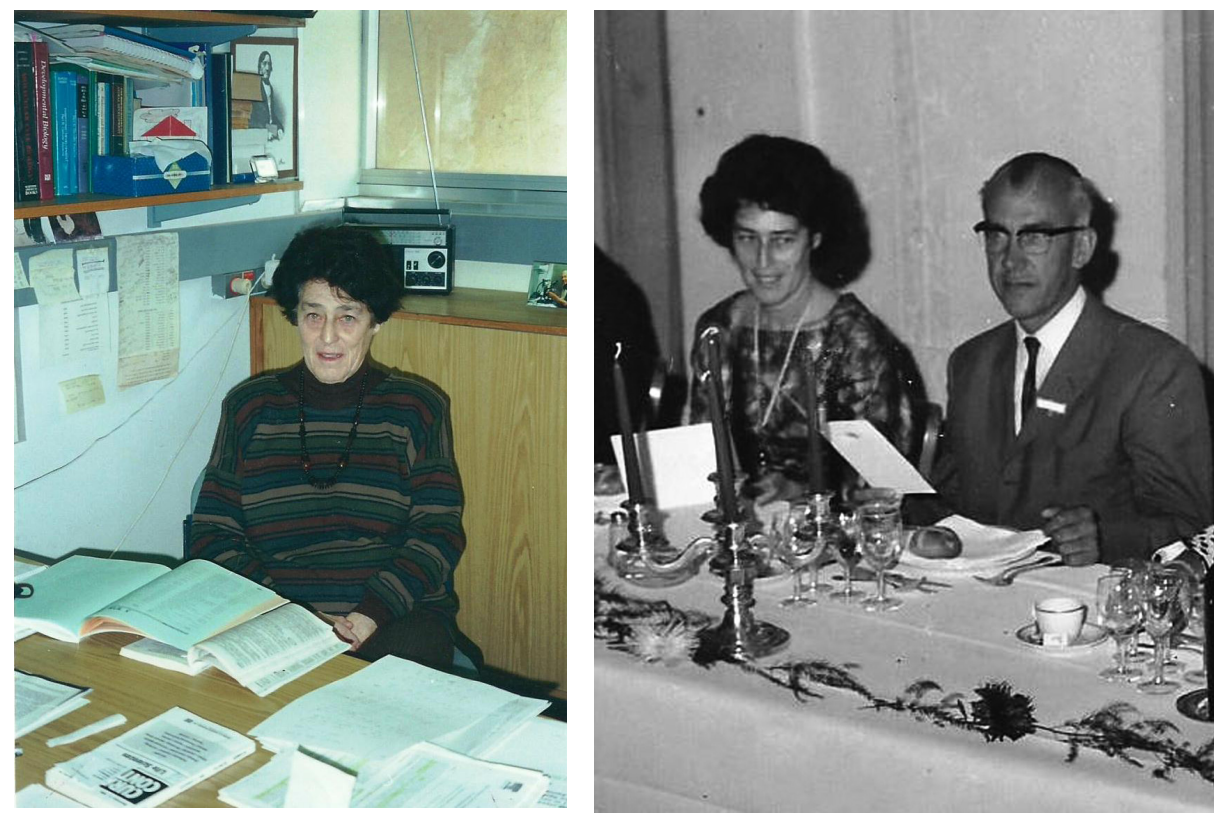

Fig. 1. Hefzibah Eyal-Giladi at her office in the Hebrew University of Jerusalem, Israel (May 2000).

Fig. 2. Hefzibah Eyal-Giladi with Pieter Nieuwkoop in Utrecht University, Netherlands (1953).

ent aspects of the early embryological stages and morphological processes of chick development. Her career-long studies would become the cornerstones of research in the field of early chick development.

\section{A table of normal stages of early chick development}

In the mid 1960's, when Hefzibah Eyal-Giladi initially started to work with early chick embryos, the only existing reference of embryonic stages was the table of Hamburger and Hamilton (H\&H; Hamburger and Hamilton, 1951). This table of normal stages included all the developmental stages of the chick from as early as the laid egg until the hatching stage, but did not include
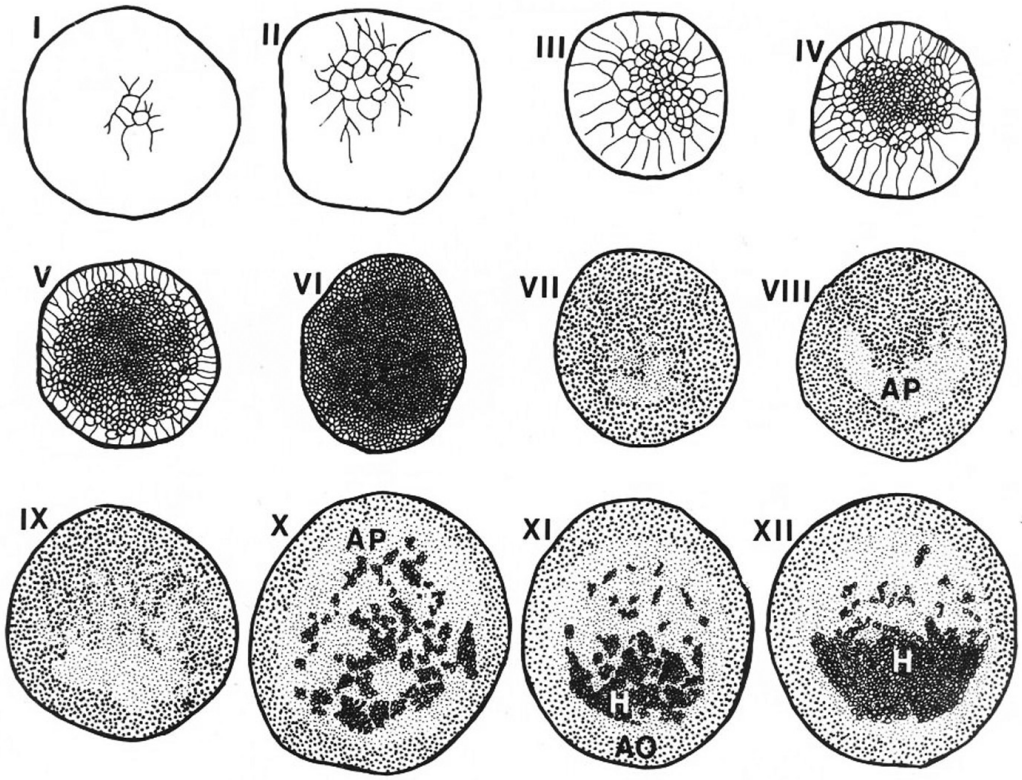

the earliest developmental stages of chick embryogenesis that take place inside the hen's uterus. Since Hefzibah Eyal-Giladi wanted to investigate the earliest stages of chick development, she and her graduate student Shimshon Kochav developed a manual method enabling them to abort intra-uterine eggs.

Eyal-Giladi and Kochav systematically examined the microscopic anatomy and cell population dynamics during the early stages of chick embryo development, and elegantly summarized these early stages in a table of normal stages (I-XIII, EG\&K). Stages I-X take place in the hen's reproductive system, and are called the intra-uterine stages, whereas stages X-XIII describe the subsequent development of the just laid egg. The detailed table of stages I-XIII that were elucidated by Eyal-Giladi and Kochav, is presented in the table of normal stages of Hamburger and Hamilton (1951), as only one stage (stage 1, H\&H). Kochav worked around the clock to manually abort the intra-uterine eggs, in order to get embryos from different developmental stages. He had to measure the exact time of the previous egg laying by the hen, in order to calculate the correct time to abort the next egg so that embryos could be obtained at the desired stages (I-X) of development.

The chick embryo develops from a disc-shaped cytoplasm (blastodisc) on top of the yolk. Eyal-Giladi and Kochav found that the egg is fertilized after ovulation, in the infundibulum, and the zygote starts to cleave five hours post fertilization, just as the egg enters the uterus. They also discovered that this cleavage stage continues for about eleven hours (stages I-VI, EG\&K), due to a very high mitosis rate in the the blastodisc. After about eleven hours of cleavage (stage VI, EG\&K), the disc-shaped cytoplasm on the top of the yolk turns into an opaque blastodisc, having a thickness of five-six cell diameters. One of the most striking events during early chick development observed by Eyal-Giladi and Kochav was the formation of the area pellucida. This is the first visible morphogenetic event in avian development, which starts at stage VII (EG\&K). While a stage $\mathrm{VI}$ blastodisc is composed of five or six cell layers, at stage VII, a directional shedding of the deep cells facing the subgerminal cavity begins. This process continues gradually during the next eight-nine hours of intra-uterine development, so that by the laid chick egg stage $X(E G \& K)$ the central area of the blastoderm is a one-cell-thick area pellucida. The cells in the peripheral ring around the forming area pellucida are attached to the yolk and form the area opaca of the blastoderm.

To further analyse the development of the laid stage

Fig. 3. Table of normal stages of chick development of Eyal-Giladi and Kochav, which includes stages I-XIII (in this figure only stages I - XII stages are shown), from cleavage to primitive streak formation. Taken from Eyal-Giladi, $H$. and Kochav. S. (1976) Dev. Biol. 49: 321-337. 
X blastoderm, Eyal-Giladi and Kochav had to incubate the eggs. They found that the formation of a lower layer of cells, the hypoblast (stages X-XIII), is the first visible morphogenetic event in the laid chick's blastoderm. At stage XIII, the formation of the hypoblast is complete, and the central disc of the blastoderm can be divided into an upper layer of cells called the epiblast, and a lower layer, called the hypoblast. This is the blastula stage of the chick embryonic development. The space between the epiblast and the hypoblast is the blastocoel cavity. Blastula stage (stage XIII) concludes the table of normal stages of chick embryo development by Eyal-Giladi and Kochav, which is still accepted worldwide as the benchmark to describe the earliest, pre- and post- egg laying stages of chick embryonic development (Fig. 3; Eyal-Giladi and Kochav 1976; Kochav et. al, 1980).

On a personal note, Shimshon Kochav was an outstanding Ph.D. student under Eyal-Giladi's mentorship. Sadly, he was killed in action in the 1973 Yom Kippur War. His Ph.D. thesis, which included the table of normal stages of chick embryo development (I-XIII), was published posthumously (Eyal-Giladi and Kochav 1976).

\section{Determining bilateral symmetry in the chick embryo}

One of the main issues concerning early avian development is how the bilateral symmetry of the embryo is determined. The unfertilized avian egg exhibits radial symmetry and is polarized along its animal-vegetal axis. When the egg is laid and starts to develop, it exhibits a clear pattern of bilateral symmetry. Eyal-Giladi and Kochav investigated this crucial process of symmetrization by focusing on the developmental stages that convert the egg from a radial to bilateral symmetry.

Conrad and Phillips (1938) demonstrated that while the chick egg is rotating during the intra-uterine stages, the shell and the albumen rotate around the stationary yolk. The blastodisc on the highest point of the yolk shifts in the direction of the rotation and therefore remains quiescent in an oblique position. Therefore, Eyal-Giladi and Kochav examined the influence of the egg's rotation on the symmetrization of the chick blastodisc. As previously mentioned, they developed a manual method that enabled them to abort intra-uterine eggs prior to the critical period of symmetrization. They could imitate the effect of rotation by taking out the yolk and hanging it on one pole in an albumen-filled beaker, thus forcing the blastodisc into an oblique position (Fig. 4). They also obtained a similar result by incubating whole aborted eggs in a vertical position, with the pointed end either up or down. In all of these experiments, Eyal-Giladi and Kochav found that the future posterior end of the embryo always coincided with the highest point of the obliquely situated radial blastodisc. Moreover, they found that the formation of the area pellucida starts from the uppermost region of the oblique blastodisc. As previously noted, at stage $\mathrm{VI}$, the blastodisc is composed of five or six cell layers and looks radially symmetric. After about 2 hours (stage VII), a directional shedding of deep cells facing the sub-germinal cavity begins from the highest point of the oblique blastodisc. This process continues gradually (stages VII-X), and the central area of the blastodisc becomes one cell layer, the area pellucida. Thus, Eyal-Giladi and Kochav found that the area pellucida forms gradually, starting with the progression in an anterior direction to the uppermost part of the blastodisc as the axis is determined. Eyal-Giladi and Kochav concluded from all of those experiments that gravity imposes

on the obliquely positioned blastodisc a gradual process of cell shedding and thereby determines the posterior-anterior axis of the chick embryo (Kochav and Eyal-Giladi, 1971; Eyal-Giladi and Fabian, 1980).

\section{Axis initiation in the chick embryo}

Another question which greatly interested Eyal-Giladi's lab was how axis formation is established in the chick embryo. Her earlier work (Kochav and Eyal-Giladi, 1971) demonstrated that a gradual process of cell shedding during the intra-uterine stages determines the posterior-anterior axis of the chick embryo. Over the years, Eyal-Giladi together with several graduate students investigated how this polarity is imposed to initiate the embryonic axis in the blastoderm.

During the early development of the chick embryo, one of the first visible regions the stage $X$ blastoderm is the marginal zone. It is a belt-like region at the periphery of the area pellucida. The marginal zone starts to appear in the posterior region of the blastoderm at stage $\mathrm{X}$, and becomes completely delineated at stage XIII, the blastula stage of the chick embryo. A sickle (Koller's Sickle) starts to form at the posterior marginal zone of the early stage $X$ blastoderm. The sickle (crescent) is a condensation of cells projected ventrally from the epiblast to form a ridge, which is the inner border of the marginal zone.

Spratt (1966) recognized the marginal zone and Koller's sickle as an area of crucial significance for embryonic development.
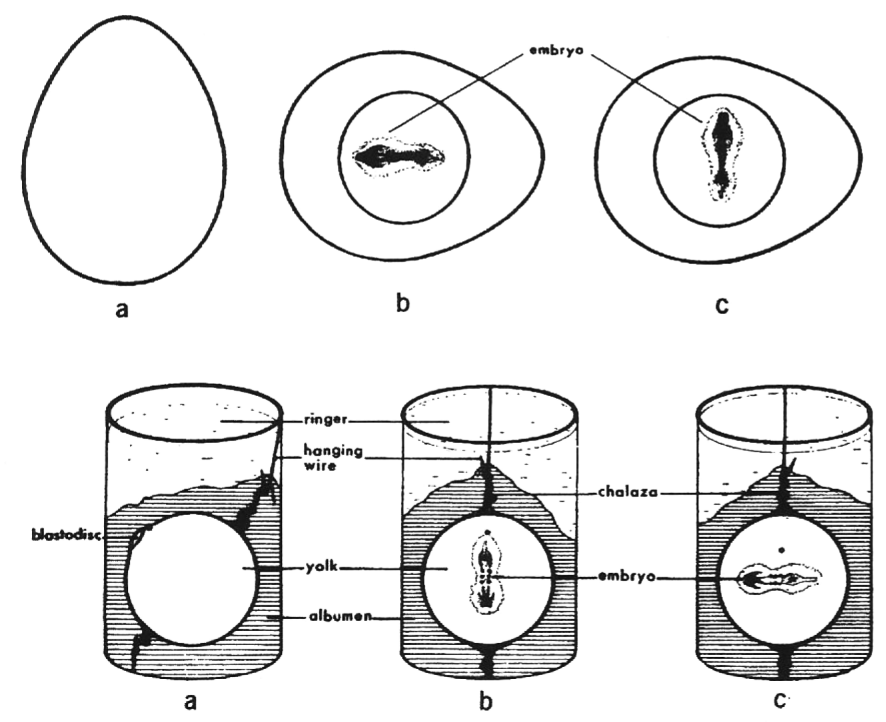

Fig. 4. The influence of the egg's rotation on the symmetrization of the chick blastodisc. (Upper $\mathbf{a}, \mathbf{b}, \mathbf{c})(\mathbf{a})$ The position of the egg during the first 10 hours of experimental incubation. (b) Uterine egg: direction of the embryo after further incubation in a horizontal position. (c) Direction of the embryo after further incubation in a horizontal position. (Lower $\mathbf{a}, \mathbf{b}, \mathbf{c})$ Experiments in which the yolk is hung by one chalaza, with the blastodisc being forced into oblique position. (a) Position of the blastodisc at the beginning of the experiment (side view). The highest point is marked with carbon. $(\mathbf{b}, \mathbf{c})$ Orientation of the embryo at the end of the experiment as related to the highest point of the blastodisc. (b) Uterine egg; (c) control egg (front view). Taken from: Kochav, S. and Eyal-Giladi, H. (1971) Bilateral symmetry in chick embryo, determination by gravity. Science. 171: 1027-1029. 
Therefore, Eyal-Giladi and Khaner elucidated the importance of the marginal-zone cells of the early chick blastoderm (stage $\mathrm{X}$ ) for axis development. They initially examined the capacity of different regions of the marginal zone to promote the formation of a primitive streak (Khaner et al., 1985; Khaner and Eyal-Giladi 1986). Two rectangular fragments of the same blastoderm, one from the posterior marginal zone (PMZ) including Koller's sickle, and one from the lateral marginal zone (LMZ), were exchanged with each other. An ectopic primitive streak developed from the $L M Z$, where the PMZ fragment had been transplanted. The main conclusion from these experiments is that at stage $X$, the cells in the $\mathrm{PMZ}$ possess the highest potency to induce development of the primitive streak and determine its location (Fig. 5).

A
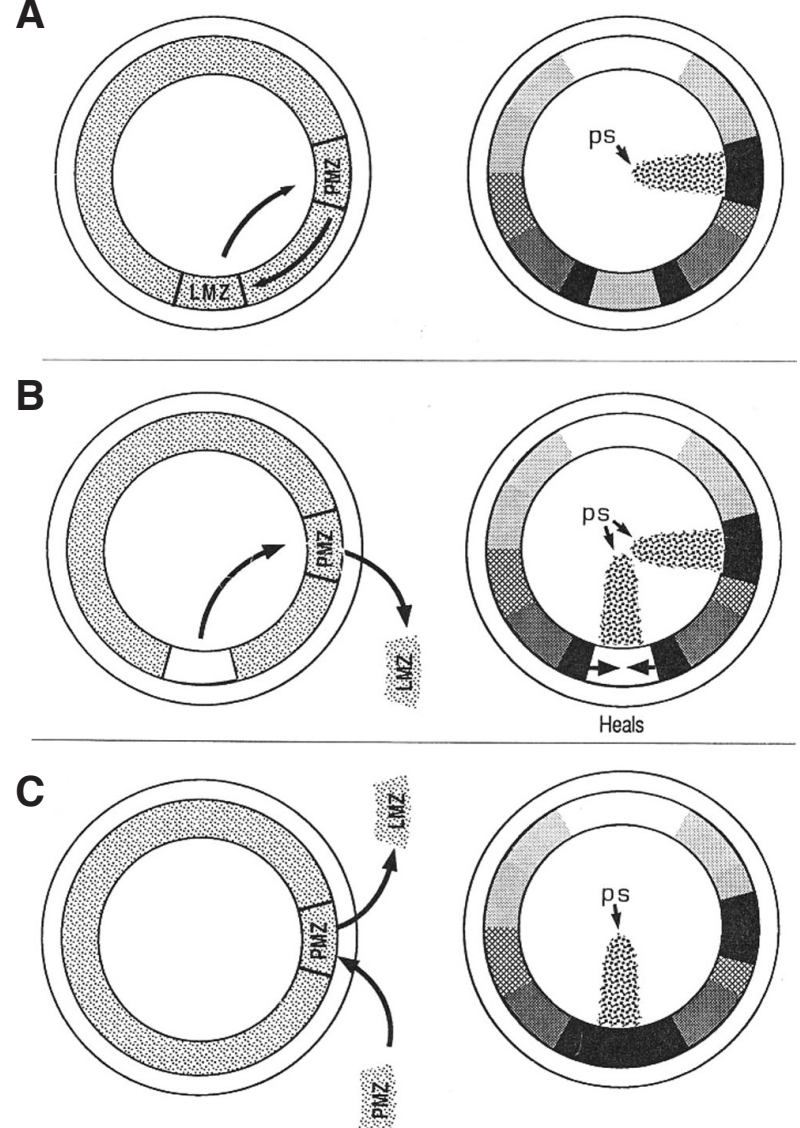

Fig. 5.The marginal zone acts as an integrative system in accordance with the regional sum of the developmental potential gradients, which include inductive and inhibitory signals. (A) Two rectangular fragments of the same blastoderm, one from the posterior marginal zone (PMZ) and one from the lateral marginal zone (LMZ), were exchanged with each other (left). An ectopic primitive streak (ps) developed from the area where the PMZ fragment was transplanted, 90 degrees from the original posterior region of the blastoderm (right). (B) The $P M Z$ fragment was transplanted to a $L M Z$, and the $L M Z$ fragment was discarded (left). The remning gap in the $P M Z$ healed, and two primitive streaks developed in the blastoderm (right). (C) A PMZ fragment from a donor blastoderm was transplanted into the lateral marginal zone of a host blastoderm that retained its original $P M Z$ (left). In this case, only one primitive streak developed, in the original posterior region of the host blastoderm (right). The degree of shading represents the inductive/inhibitory capacity. Taken from: Khaner, O. (1993). Axis determination in the avian embryo. Curr Top Dev Biol. Vol. 12 155-180.
To further examine the issue of axis initiation, Eyal-Giladi and Khaner conducted various experiments, including homoplastic and heteroplastic transplantations (Khaner and Eyal-Giladi 1989; Eyal-Giladi and Khaner 1989). From these experiments, they concluded that a gradient of developmental potential to form a primitive streak is expressed within the marginal zone area of stage $X$ blastoderms. The blastoderm during the early stages of development acts as an integrative system programmed to form a single embryonic field by the coordinated action of inductive and inhibitory effects. Moreover, the posterior marginal zone can be thought as an organizing center analogous in some ways with the Nieuwkoop center in amphibians (Bertocchini et al., 2004), since it can induce the formation of a new embryonic axis.

\section{Mesoderm induction}

Historically, mesoderm induction was one of the main topics of investigation in early amphibian development (Nieuwkoop, 1985), and Eyal-Giladi was the pioneer researcher of this subject in the avian embryos. In the chick, the first visible tissue that develops as a result of mesoderm induction is the primitive streak. However, its induction already occurs during the stages of hypoblast formation. Therefore, Eyal-Giladi and Azar conducted a set of experiments at those stages to unravel this apparent discrepancy. They examined the functional role of different regions of the stage XIII blastoderm, and their involvement in the formation of the primitive streak and subsequent induction of mesoderm (Azar and Eyal-Giladi 1979; Azar and Eyal-Giladi 1983).

They systematically examined the interactions of the epiblast with the hypoblast and/or the marginal zone. In the stage XIII blastoderm, the formation of the hypoblast is complete, and the central disc of the blastoderm can be divided into two layers, the hypoblast and the epiblast. At this stage, the marginal zone has a distinct outer border, the area opaca, and inner border, the central disc. Azar and Eyal-Giladi removed from the blastoderm, the area opaca, the marginal zone, the hypoblast, or both the hypoblast and the marginal zone, and cultured the remaining parts. When the area opaca was removed from the stage XIII blastoderm, the primitive streak formed normally. Removal of the area opaca and the adjacent marginal zone, or removal of the hypoblast itself also did not influence the formation of the primitive streak. However, when both the marginal zone and the hypoblast were removed, the primitive streak did not develop, although some mesodermal derivatives were formed (blood vessels and blood islands). Azar and Eyal-Giladi concluded that either the hypoblast or the marginal zone must be present at stage XIII for the primitive streak to form. In the absence of both the marginal zone and the hypoblast, the isolated epiblast could form some non-axial mesoderm, which was already induced during earlier stages (X-XII). However, because this induction was weak, axial mesoderm structures did not form.

These results suggested that the induction of the mesoderm is a multi-step specification process. In normal development in the presence of the marginal zone, the hypoblast, or both, the induction process is continuous and results in the formation of the primitive streak and all mesoderm derivatives. If the epiblast of the chick embryo is exposed for only a short time to the inductive influences during its formation (stages X-XII), the level of this inductivity is not sufficient to form the primitive streak and axial 
mesoderm. In this case, only non-axial mesoderm (blood vessels and blood islands) is formed in the isolated epiblasts.

\section{Avian primordial germ cells}

The origin of the Primordial Germ Cells (PGCs) in invertebrates and in some vertebrates (fish and amphibians) is known to arise from germ plasm. In amniotes (reptile, avian and mammalian), the PGCs were known to form by induction, but their origin was unclear. Eyal-Giladi and colleagues were the first to discover that the avian PGCs are of an epiblastic origin (Eyal-Giladi et al., 1981). They also found that the PGCs begin to migrate from the epiblast towards the hypoblast, a process that continues throughout the entire gastrulation period, until about the stage of head-fold formation (Ginsburg and EyalGiladi, 1986). The migrating PGCs are carried both by the hypoblast and mesoderm into the germinal crescent, where most of them are to be found at stage $10 \mathrm{H} \& \mathrm{H}$ (Hamburger and Hamilton, 1951).

Moreover, Eyal-Giladi and Ginsburg examined the existence of a specific area in the early chick blastoderm, which might be the exclusive source of PGCs. They divided the chick blastoderm into fragments, incubating them for forty-eight hours, after which the fragments were analyzed for the presence of PGCs. They found that most of the PGCs originated from the central fragment of the chick blastoderm (epiblast). The PGCs were derived from this fragment even in the absence of embryonic axis development. The PGCs were found mostly in association with the forming blood islands. When an embryonic axis did develop in some fragments, the PGCs were concentrated in its anterior end, in a pattern resembling the germinal crescent. In addition, no indication of a quantitative regulation of the PGCs was found, and the sum of PGCs was almost constant. These results demonstrated for the first rime that PGCs may be determined in the epiblast as early as the stage of laid egg $(\mathrm{X})$, and that the further differentiation of the PGCs is independent of the embryonic forming processes (Ginsburg and EyalGiladi, 1987).

Fig. 6. Sagittal sections of blastula embryos. The proposed homology of blastulae and the gradual formation of their mesoderm-inducing centers. (A) A holoblastic blastula, in which Nieuwkoop's center is the inducer of the organizer. (B-E) are four proposed types of meroblastic blastuale: (B) fish; (C) meroblastic amniota; (D) marsupialia; (E) eutherian mammal. Taken from: Eyal-Giladi, $H$. (1997). Establishment of the axis in chordates: facts and speculations. Development 124: 2285-2296.

\section{Establishment of the body axis in chordates}

Eyal-Giladi was also interested in central questions of comparative embryology and evolution. She was attracted to how the embryonic axis is established in different chordates, especially in vertebrates. A review article she wrote on this important issue was dedicated to the memory of Pieter D. Nieuwkoop, who was her beloved teacher, mentor and friend, and as she wrote, " a great, but modest scientist".

Eyal-Giladi proposed a master plan for the early development of all chordates and vertebrates (Eyal-Giladi, 1997). It is well known that a common feature for all chordates and vertebrates is that the animal-vegetal axis is probably the only axis that is determined during oogenesis, so that at ovulation the ovum is radially sym-
PRIMARY HOLOBLASTIC

\section{A Amphibia}

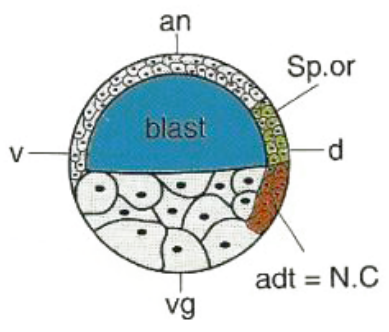

\section{MEROBLASTIC OPTIONS}

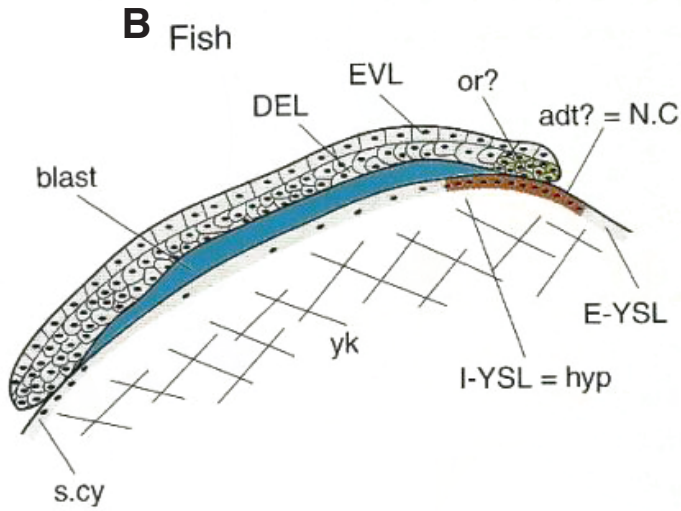

C

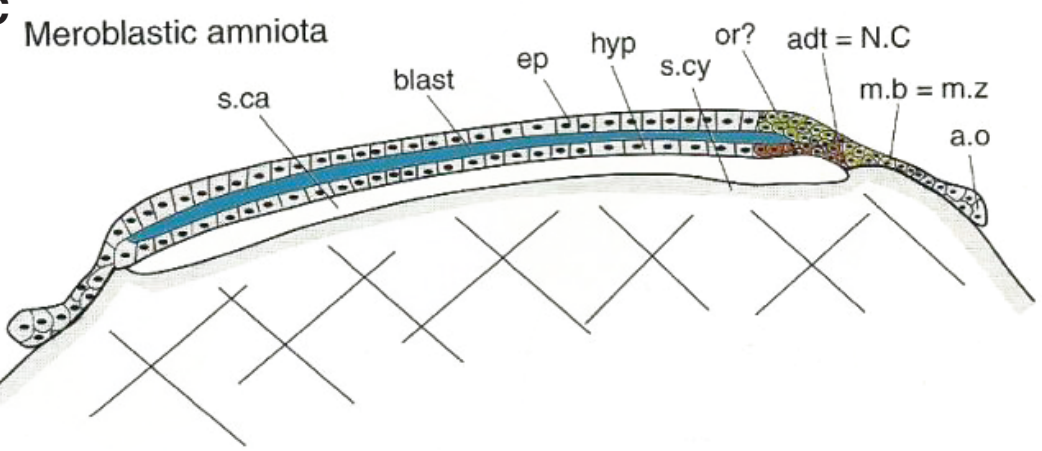

\section{HOLOBLASTIC VARIATION OF MEROBLASTIC OPTION}

D
E Eutherian mammals

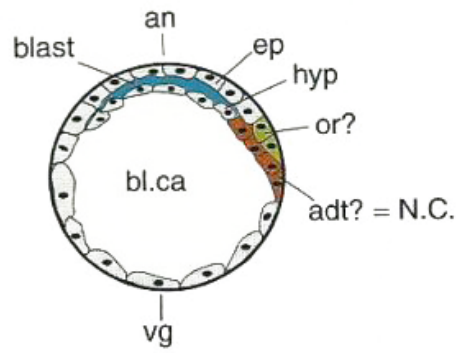

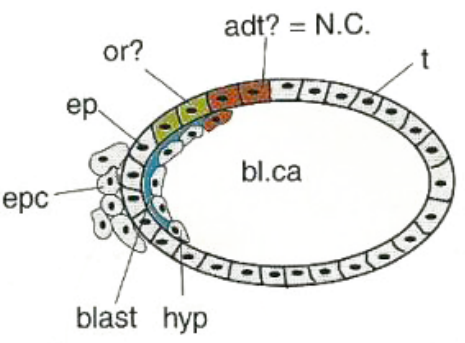


metric. The establishment of the bilaterally symmetric embryonic axis (axialization) is an event that takes place after fertilization. Eyal-Giladi suggested that the speed of axialization seems to be related to amount of yolk in the ovum.

Experiments in amphibians and avian embryos demonstrated that the radial symmetry of the ovum is changed at or after fertilization into bilateral symmetry by an external signal. Two alternative triggers, sperm entry (in amphibian) and gravitation (in avian) have been demonstrated. Eyal-Giladi suggested that a correlation exists between the amount of yolk stored in the fertilized ovum and the mechanism used for axialization. She proposed that the speed at which axialization of the embryo takes place depends on the translocation speed of maternal determinants. These determinants move from the vegetal pole of the fertilized ovum towards the future dorso-posterior side of the embryo. On arrival at their destination, the activated determinants form an induction center. This center is homologous to the amphibian "Nieuwkoop Center". In all chordates and vertebrates, the "Nieuwkoop Center" induces the formation of an organizer equivalent to the amphibian "Spemann Organizer" (Fig. 6; Eyal-Giladi, 1997). The line connecting the midline of the organizer and the animal pole will inevitably become the median plane of the future embryo, and the head will therefore develop at or towards the animal pole. According to Eyal-Giladi, only a clear understanding of the morphogenetic homologies in a broad spectrum of chordates and vertebrates embryos can provide the basis for comparative study of the location and role of developmental molecules during early development.

\section{References}

AZAR, Y. and EYAL-GILADI, H. (1979). Marginal zone cells, the primitive streakinducing component of the primary hypoblast in the chick. J. Embryol. Exp. Morphol. 52: 79-88.

AZAR, Y. and EYAL-GILADI, H. (1983). The relation of primary hypoblastic cells underneath the developing primitive streak allows for their prolonged inductive influence. J. Embryol. Exp. Morphol. 77: 143-151.

BERTOCCINI, F., SKROMNE, I., WOLPERT, L. and STERN, C.D. (2004). Determination of embryonic polarity in a regulative system: evidence for endogenous inhibitors acting sequentially during primitive streak formation in the chick embryo. Development. 131: 3381-3390.

CONARD, R. and PHILLIPS, R.E. (1938). The formation of the chalazae and the inner thin white in the hen's egg. Poultry Sci.. 17: 143-146.

EYAL-GILADI, H. (1954). Dynamic aspects of neural induction in amphibia. Arch Biol (Liege). 65: 179-259.

EYAL-GILADI, H., EYAL, Z. and ESHEL, S. (1964). A microscopic study of chlorpromazine (largactil) on treated axolotl larvae. J Embryol Exp Morphol. 12: 447-56.

EYAL-GILADI, H. and SPRATT, N.T. (1965). The embryo forming potencies of the young chick blastoderm. J. Embryol. Exp. Morphol. 13: 267-273.
EYAL-GILADI, H. (1969). Differentiation potencies of the young chick blastoderm as revealed by different manipulations. I. Folding experiments and position effect of the culture medium. J. Embryol. Exp. Morphol. 13: 177-192.

EYAL-GILADI, H. (1970). Differentiation potencies of the young chick blastoderm as revealed by different manipulations. II. Localized damage and hypoblast removal experiments. J. Embryol. Exp. Morphol. 23: 739-749.

EYAL-GILADI, H. (1970). Competence and induction in the pre-gastrula chick blastoderm study of Siamese twins formed in folded blastoderms. Annale d'Embryol. et de Morphog. 3: 133-143.

EYAL-GILADI, H. and KOCHAV.S. (1976). From cleavage to primitive streak formation: a complementary normal table and a new look at the first stages of the development of the chick. I. General morphology. Dev. Biol. 49: 321-337.

EYAL-GILADI, H. and FABIAN, B. (1980). Axis determination in uterine chick blastodiscs under changing spatial positions during the sensitive period for polarity. Dev. Biol. 77: 228-232.

EYAL-GILADI, H., GINSBURG, M. and FARBAROV, A. (1981). Avian primordial germ cells are of epiblastic origin. J. Embryol. Exp. Morphol. 65: 139-147.

EYAL-GILADI, H. and KHANER, O. (1989). The chick's marginal zone and primitive streak formation. II. Quantification of marginal zone's potencies-temporal and spatial aspects. Dev. Biol. 134: 215-221.

EYAL-GILADI, H. (1997). Establishment of the axis in chordates: facts and speculations. Development 124: 2285-2296.

GINSBURG, M. and EYAL-GILADI, H. (1986). Temporal and septial aspects of the gradual migration of primordial germ cells from the epiblast into the germinal crescent in the avian embryo. J. Embryol. Exp. Morphol. 95: 53-71.

GINSBURG, M. and EYAL-GILADI, H. (1987). Primordial gerem cells of the young chick blastoderm originate from the central zone of the area pellucida irrespective of the embryo-forming process. Development 101: 209-219.

HAMBURGER, V. and HAMILTON, H.L. (1951). Stages in the development of the chick embryo. J. Morphol. 88: 49-92.

KHANER, O., MITRANI, E. and EYAL-GILADI, H. (1985). Developmental potencies of the area opaca and the marginal zone areas of the early chick blastoderms. J. Embryol. Exp. Morphol. 89: 235-241.

KHANER. O, and EYAL-GILADI, H. (1986). The embryo forming potency of the posterior marginal zone in stage $\mathrm{X}$ through XII of the chick. Dev. Biol. 115: 275-281.

KHANER. O, and EYAL-GILADI, H. (1989). The chick's marginal zone and primitive streak formation. I. Coordinative effect of induction and inhibition. Dev. Biol. 134: 206-214.

KHANER. O. (1993). Axis determination in the avian embryo. Curr Top Dev Biol. 12: $155-180$

KOCHAV, S. and EYAL-GILADI, H. (1971). Bilateral symmetry in chick embryo, determination by gravity. Science 171: 1027-1029.

KOCHAV, S., GINSBURG, M. and EYAL-GILADI, H. (1980). From cleavage to primitive streak formation: a complementary normal table and a new look at the first stages of the chick. II. microscopic anatomy and cell population dynamics. Dev. Biol. 79: 296-308.

NIEUWKOOP, P.D. (1985). Inductive interactions in early amphibian development and their general nature. J. Embryol Exp Morphol. 89 Suppl: 333-347.

SPRATT, N.T. (1966). Some problems and principles of development. Am. Zoologists. 6: 215-254. 


\section{Further Related Reading, published previously in the Int. J. Dev. Biol.}

The involvement of three signal transduction pathways in botryllid ascidian astogeny, as revealed by expression patterns of representative genes

Amalia Rosner, Gilad Alfassi, Elizabeth Moiseeva, Guy Paz, Claudette Rabinowitz, Ziva Lapidot, Jacob Douek, Abraham Haim and Baruch Rinkevich

Int. J. Dev. Biol. (2014) 58: 677-692

From Agrobacterium to viral vectors: genome modification of plant cells by rare cutting restriction enzymes Ira Marton, Arik Honig, Ayelet Omid, Noam De Costa, Elena Marhevka, Barry Cohen, Amir Zuker and Alexander Vainstein Int. J. Dev. Biol. (2013) 57: 639-650

What Hydra can teach us about chemical ecology - how a simple, soft organism survives in a hostile aqueous environment Tamar Rachamim and Daniel Sher

Int. J. Dev. Biol. (2012) 56: 605-611

Analysis of chemotaxis when the fraction of responsive cells is small - application to mammalian sperm guidance Anna Gakamsky, Edna Schechtman, S. Roy Caplan and Michael Eisenbach

Int. J. Dev. Biol. (2008) 52: 481-487

Mouse models to study inner ear development and hereditary hearing loss Lilach M. Friedman, Amiel A. Dror and Karen B. Avraham

Int. J. Dev. Biol. (2007) 51: 609-631

The importance of the posterior midline region for axis initiation at early stages of the avian embryo

Oded Khaner

Int. J. Dev. Biol. (2007) 51: 131-137

Early stages of neural crest ontogeny: formation and regulation of cell delamination Chaya Kalcheim and Tal Burstyn-Cohen

Int. J. Dev. Biol. (2005) 49: 105-116

Allogeneic interactions in Hydractinia: is the transitory chimera beneficial? Sharon Gild, Uri Frank and Ofer Mokady

Int. J. Dev. Biol. (2003) 47: 433-438

High proliferation rate characterizes the site of axis formation in the avian blastula-stage embryo.

N Zahavi, V Reich and O Khaner

Int. J. Dev. Biol. (1998) 42: 95-98
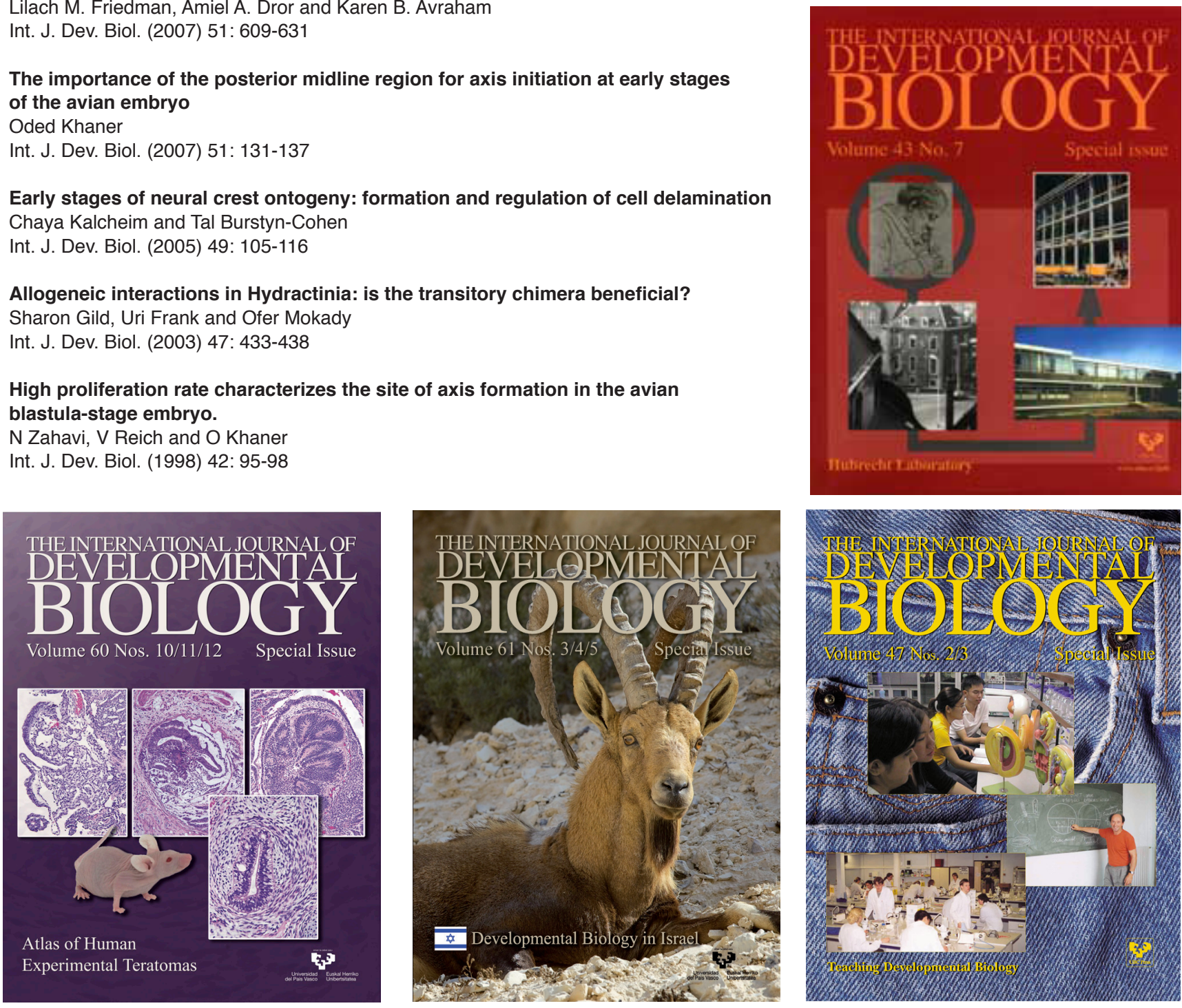